\title{
BATUQUE, ARTE E EDUCAÇÃO NA COMUNIDADE QUILOMBOLA SÃO PEDRO DOS BOIS.
}

\author{
Clícia Tatiana Alberto COELHO ${ }^{1}$ \\ Universidade Federal do Amapá - UNIFAP \\ cliciacoelho@gmail.com \\ Raimundo Erundino Santos DINIZ ${ }^{2}$ \\ Universidade Federal do Amapá- UNIFAP \\ derundinosantos@yahoo.com.br.
}

Resumo: Este artigo revela diferentes sentidos educacionais da manifestação sociocultural anunciada como Batuque existente na comunidade quilombola São Pedro dos Bois, localizada no Estado do Amapá/BR 156, a 75 km de distância da capital, Macapá. Entrelaça saberes das linguagens artísticas e suas visualidades, corporidades e simbologias inerentes a essa manifestação, compreendidos como discursos de firmamento da cultura quilombola no cotidiano escolar da comunidade. A metodologia utilizada anuncia-se interdisciplinar por possibilitar diálogos entre História, Artes e Educação, utilizando-se de diferentes abordagens e técnicas de pesquisas mediadas por narrativas (orais $\mathrm{e}$ imagéticas) e outros documentos levantados em pesquisa de campo.

Palavras-chaves: Batuque; Educação; Visualidades; Quilombola.

\begin{abstract}
This article reveals different educational meanings of sociocultural event announced as "Batuque" existing in quilombola community of São Pedro dos Bois, located in the State of Amapá / BR 156, $75 \mathrm{~km}$ away from the capital Macapá. Interweaves knowledge of artistic languages and their visualities, corporeity and symbology inherent in this event, understood as firmament speeches of quilombola culture in the school community's routine. The methodology used is announced by enabling interdisciplinary dialogues between History, Arts and Education, using different approaches and research techniques mediated by narratives (oral and imagetic) and other documents collected in the field of research.
\end{abstract}

Key words: Batuque; Education; Visualities; Quilombola community

\footnotetext{
${ }^{1}$ Mestre em Artes Visuais (UFPB). Docente do Curso de Pedagogia da Universidade Federal do Amapá (UNIFAP). Integrante do Grupo de Estudo e Pesquisa Interdisciplinar em Educação e Saberes da Amazônia Amapaense (GEPIESA/UNIFAP) e do Grupo de Pesquisa em Ensino das Artes Visuais (GPEAV/UFPB).. ${ }^{2}$ Historiador. Doutorando em Ciências Socioambientais (NAEA/UFPA). Mestre em Planejamento do Desenvolvimento Sustentável do Trópico Úmido (NAEA/UFPA). Docente do Curso de Pedagogia da Universidade Federal do Amapá (UNIFAP). Integrante do Grupo de Estudo e Pesquisa Interdisciplinar em Educação e Saberes da Amazônia Amapaense (GEPIESA/UNIFAP). Pesquisador do Projeto Nova Cartografia Social da Amazônia - PNCSA.
} 


\section{Introdução}

As reflexões apresentadas no artigo surgiram da necessidade de analisar como a manifestação cultural do Batuque se evidência na prática escolar e extraescolar da comunidade quilombola São Pedro dos Bois, localizada no Estado do Amapá/BR 156. Pois investigar como essa prática social se desenvolveu, considerando o seu legado histórico e cultural, material e imaterial, herdado de seus ancestrais africanos e afroamapaenses nos ajuda a compreender continuidades e descontinuidades desse fazer na contemporaneidade. Trata-se de uma pesquisa qualitativa etnográfica, tendo como geração de dados à realização de entrevistas, observações de campo e análise documental triangulados com abordagens teóricas que discutem sobre arte, educação, história, cultura e sociedade.

A pesquisa aborda aspectos históricos e os relaciona com as práticas sociais ocorridas dentro e fora do ambiente educativo formal, instaurados a partir de saberes das linguagens artísticas e suas visualidades, corporidades e simbologias intrínsecas a essa manifestação, concebidos como discursos afirmativos da cultura quilombola no cotidiano da comunidade.

\section{Comunidade São Pedro dos Bois: territorialidade, tradição e resistência negra.}

A comunidade quilombola São Pedro dos Bois pertencente ao município de Macapá, Estado do Amapá e tem como principal via de acesso as BR 210 e BR 156, com entrada no quilometro 50, seguindo por mais $25 \mathrm{~km}$ no ramal de estrada de chão, conferindo-lhe $75 \mathrm{~km}$ de distância da capital. São Pedro dos Bois registra nos documentos cartoriais o ano de 1893 o ano de fundação do povoado, vizinho a outras comunidades quilombolas, com maior proximidade à comunidade quilombola do Ambé separadas apenas por um rio, conhecido como "Igarapé do Inferno".

As compreensões sobre comunidades quilombolas contemporâneas ${ }^{3}$ referem terras tradicionalmente ocupadas e reconhecidas na Constituição de 1988 como de

\footnotetext{
${ }^{3}$ Almeida (2008, p.48) assinala que: Em 1988 o conceito de 'terras tradicionalmente ocupadas', vitorioso nos debates da Constituinte, tem ampliado seu significado, coadunando-o com os aspectos situacionais, que caracterizam hoje o advento de identidades coletivas. Este se tornou um preceito jurídico marcante para a legitimação de territorialidades específicas etnicamente construídas.
} 
propriedades definitivas que devem ser tituladas pelo Estado como pertencentes aos quilombolas, conforme decreto 4887/03. Este decreto prevê ao Estado a responsabilidade direta na identificação, reconhecimento, delimitação, demarcação e titulação das terras ocupadas por remanescente das comunidades de quilombos. Visando intervenções governamentais mais aceleradas e ágeis para garantir os direitos de propriedades coletivas quilombolas; anseio que tem encontrado muitos entraves no Estado do Amapá, sendo de igual modo, o reflexo de todo o território nacional.

São Pedro dos Bois, assim como outras comunidades tradicionais, tem enfrentado enormes obstáculos para garantir a titulação definitiva do seu território e sofre ameaça em relação à manutenção do seu patrimônio natural, sobretudo, as áreas de uso comum ${ }^{4}$, voltadas ao extrativismo, a pesca, a pequena agricultura e ao pastoreio. Da mesma forma, encontra enormes desafios para recuperar e preservar seus patrimônios de ordem material e imaterial.

Para o Instituto de Patrimônio Histórico e Artístico Nacional (Iphan), patrimônio material define-se como um conjunto de bens culturais de natureza arqueológica, paisagística e etnográfica; histórica; artefato das belas artes e/ou das artes aplicadas. E o patrimônio imaterial constitui-se de "saberes, os ofícios, as festas, os rituais, as expressões artísticas e lúdicas, que, integrados à vida dos diferentes grupos sociais, configuram-se como referências identitárias na visão dos próprios grupos que as praticam" (Castro, 2008, p.12). Neste interim, justifica-se a magnitude do Batuque como instrumento de luta e valorização da cultura imaterial quilombola, instrumentalizada no fazer escolar.

Em entrevista5, João Batista Barbosa Fortunato, conhecido como "Paredão", presidente da comunidade no período vigente ao início do processo de registro da Associação quilombola, informou ter sido declarante da Associação de Agricultores de São Pedro dos Bois e que assinou a solicitação que deu início aos procedimentos para a

\footnotetext{
${ }^{4} \mathrm{O}$ território compartilhado coletivamente entre as famílias quilombolas em São Pedro dos Bois garante a reprodução social com atividades de pesca, criação de pequenos gados, caça de pacas, tatus, veados, antas, jabuti, dentre outros animais, como também extrativismo de palhas, ouriços, cascas e madeiras. As casas de farinha individuais e coletivas para fabricação de uso comunitário referendam modalidades de saber, fazer, ser e criar singulares e práticas de apropriações coletivas e comuns das propriedades da natureza em território de uso comunitário.

${ }^{5}$ Entrevistas de campo semi estruturada realizadas com João Batista Barbosa Fortunato e Anny Picanço Barbosa em Setembro de 2015. 
titulação junto à Fundação Cultural Palmares, entidade responsável pelo certame, com publicação do Diário Oficial da União registrada no dia 04 de março de 2004. Sendo que, a emissão do termo de Certificação da comunidade quilombola São Pedro dos Bois só ocorreu em 20 de março de 2006 e até o presente momento aguardam o fechamento do processo com a entrega do documento de titulação. A certificação da comunidade Quilombola São Pedro dos Bois veio acompanhada, ainda no final de 2005, de projetos vinculados ao Programa Brasil Quilombola ${ }^{6}$, como políticas públicas específicas para atender as necessidades das famílias do lugar. Com essas ações pretende-se titular uma área aproximada de nove quilômetros entre os extremos norte/sul com previsão de aproximadamente trinta e cinco famílias beneficiadas.

São Pedro dos Bois está entre as comunidades quilombolas mapeadas pelo projeto "Comunidades Duráveis", expressão que indica referências históricas de ocupações quilombolas dos territórios às margens dos rios Matapi e Pedreira. São importantes rios para a compreensão dos processos de ocupações de várias áreas relativas à própria história do Estado do Amapá. As histórias de formações de comunidades quilombolas remontam experiências e vivências em circuitos de rios, igarapés, lagos e portos como cenários de trocas comerciais, confabulações, fontes de alimentos, resistências, rotas de fugas, recuperados nas narrativas dos mais idosos.

Conforme Oliveira (2012) o processo de formação histórica do povoado São Pedro dos Bois alude ao encontro de duas mulheres que passaram a ser consideradas matriarcas da comunidade: Gregória, negra vinda da África na condição de escrava e fugitiva da Fortaleza de São José de Macapá, e, Ana Mininea Barriga, uma portuguesa, fazendeira, proprietária de terras e cabeças de bois na região e em outra região próxima conhecida como Mangaba.

\footnotetext{
${ }^{6}$ A comunidade de São Pedro dos Bois vem se destacando por sua luta, para requerer seus direitos, um exemplo é a viabilização de projetos como o "Minha casa, minha vida" do Governo Federal, através destes projetos também esta sendo construído um prédio novo para a escola. Em relação ao programa de moradia do Governo Federal, a comunidade foi a primeira na região norte e a segunda no Brasil a ser contemplada com as moradias. Registra Lorena Souza em atividade de campo.

7 Este projeto objetivava elaborar relatórios antropológicos de caracterização histórica, econômica, ambiental e sócio cultural da comunidade São Pedro dos Bois organizado pela antropóloga Maria do Socorro dos Santos Oliveira através da parceria com a Fundação Universidade Federal do Amapá (UNIFAP) / Agência de Desenvolvimento do Amapá (ADAP). Elaborado em 2012 vinculou-se ao projeto "Comunidades Duráveis" com objetivo de incentivar o processo de regularização fundiária de seis comunidades quilombolas do Amapá como peça anexada a documentação do processo de titulação com vias aos processos de organizações territoriais das comunidades quilombolas do Estado.
} 
Ana Barriga, conhecida como "Anica Barriga", teria se aproximado de Gregória para organizar o povoado e conciliar a criação de bois que também já era praticada pelas famílias de negros e negras que ocupavam aquelas terras. Esses dados são reforçados pelo o relatório técnico antropológico do Instituto Nacional de Colonização e Reforma Agrária (INCRA) elaborado em 2005, construído a partir das narrativas coletadas na comunidade, levando a inferir que o encontro dessas mulheres conflui com um conjunto de elementos característicos da história do Amapá, da história da escravidão negra no Amapá, da história dos processos de domínios e organização territorial por grupos de negros e negras, por outras interfaces das relações escravistas na região norte do Brasil.

A partir do exposto, são encontradas pistas importantes das modalidades de ocupações econômicas e formações sócio culturais de povoados, vilas, lugares e distritos com ações diretas de negros e negras nas condições de escravos, aquilombados, mocambeiros e/ou libertos(as). Entre os aspectos salientes pode-se considerar a importância das relações de gêneros onde as mulheres sobressaem na condição de matriarcas reforçando a necessidade em recontar parte da história da Amazônia a partir da atuação feminina em diferentes perspectivas. A história de São Pedro dos Bois informa correlações no jogo de interesses $^{8}$, entre a fazendeira Ana Barriga e a escrava foragida Gregória, pelas terras e criações existentes na região em uma temporalidade histórica ainda muito marcada pelo patriarcalismo, patrimonialismo e diferenciação racial.

Pode-se então considerar que a adoção de nomes de "Santos" para representar povoados e depois comunidades quilombolas na Amazônia ou mesmo o recebimento de imagens para serem veneradas em unidades domésticas, barracões e depois em igrejas construídas a partir da fé e trabalho das famílias nem sempre tiveram como mediadores membros oficiais da igreja católica ou a ela correlata. Nas histórias de quilombos encontram-se histórias de propagações do catolicismo conforme anseios, estratégias e

\footnotetext{
${ }^{8}$ Outro elemento indicativo refere ao fato de que nem sempre senhores e escravos ou senhoras e escravas ocuparam posições opostas alimentadas por tensões, disputas e conflitos. Muitos mocambos e quilombos na Amazônia surgiram de situações sociais de convergências, negociações, conciliações, doações e mesmo alianças devido aos diferentes níveis de articulações, mobilizações e conquistas de autonomias por parte de escravos, libertos e libertinos junto a senhores de engenhos, fazendeiros e autoridades públicas e religiosas. ${ }^{9}$ De outro lado, os ritos e práticas religiosas trazidas por ambas às matriarcas sinalizam mais uma faceta a pretensa preponderância do catolicismo divulgado como referência de evangelização diretamente atrelado ao projeto de colonização. A Preparação das festividades de "Santos" demonstram que na Amazônia a história do catolicismo não pode ser compreendida apenas pelas missões religiosas, constituições de igrejas, paróquias e prelazias, ou mesmo, por relações de tutelas ligadas a relações de obediências as realizações de ritos ministrados por parte do clero secular ou regular.
} 
interesses característicos de cada temporalidade e situações sociais específicas elaboradas no interior das crenças quilombolas.

Em são Pedro dos Bois a atuação Ana Barriga fez surgir à festividade de São Pedro dos Bois sugerindo o nome do povoado e o padroeiro a ser adotado. De outra forma, Gregória manifestava em seus antecedentes o culto a São Raimundo como referência as comemorações festivas do povoado. Na memória dos mais idosos existem indefinições sobre as preferências, alguns consideram que a inclusão de "bois" a festividade de São Pedro serviu apenas para aludir à imagem da fazendeira, outros preferem manter a tradição à festividade de São Raimundo como principal evento. Em ambas as festividades o Batuque encontra-se de forma transversal simbolizando momento importante das ritualísticas que compõem as práticas festivas e crenças.

\section{Batuque e Marabaixo: ancianidade africana}

A história e memória da comunidade quilombola São Pedro dos Bois deve ser compreendida a partir de um conjunto de relações sociais, econômicas, culturais e religiosas à medida que as narrativas e os documentos apontam para práticas de cultivos, criações, cultos, ritos e mitos singulares. A memória histórica manifestada por parte dos quilombolas dessa comunidade recupera e insinua a elaboração de códigos de linguagens específicos pautados nas maneiras de dançar, interagir, falar, saber e viver que povoam as memórias de distintas gerações reveladas por visualidades em manifestações como o Batuque - fortemente apropriado como cultura comunitária ligada a identidade quilombola ancestral.

Quando falamos de visualidades nos reportamos, principalmente, às ideias exploradas por Martins (2009) referindo-se a um processo de sedução, rejeição e cooptação que se desenvolve a partir de imagens com origem na experiência visual; e, Nascimento (2011), que servindo-se dos enunciados foucaultianos, entende visualidades como interpretações visuais construídas historicamente pelos sujeitos em diferentes épocas. Que podem ser percebidas como regimes de enunciação visual ou os modos como passamos a ver, pensar, dizer e fazer de determinada maneira e não de outra. $\mathrm{Na}$ compreensão que o batuque praticado na comunidade São Pedro dos Bois, também, é um processo histórico de experiências e interpretações visuais que se reconstroem na contemporaneidade a partir de seu legado. 
Entre as práticas culturais encontradas dentre os quilombolas em São Pedro dos Bois estão às festividades de "Santos" o Marabaixo" e o Batuque com maior ênfase, ambas as atividades reproduzem-se elementos singulares da cultura afro-brasileira e "afro-indígena" (descendência africana e indígena) do Amapá. Estas práticas e rituais são encontradas também em vários registros da história do Grão Pará (segunda metade do século XIX) em temporalidades distintas e responsáveis por continuidades e permanências de tradições na Amazônia contemporânea nos Estados do Amazonas, Pará e Maranhão com versões e linguagens diferenciadas.

Salles (2003) em "O vocabulário Crioulo" apresenta uma larga descrição sobre a história do Batuque e seus possíveis desdobramentos em diversos rituais africanos e afroindígenas. Demonstra que a dança e o uso do tambor ou de vários tambores sempre esteve ligado aos folguedos e folias de negros escravos libertos e mestiços. $\mathrm{O}$ autor faz referência aos registros de Spix e Martius (1820) quando se reportam ao batuque como manifestações de lasciva e prazerosa dança características dos negros. Da mesma forma, assinala que existem registros no Maranhão, catalogado pelo Frei Francisco de Nossa Senhora dos Prazeres, falando das reuniões de negros em danças, batuques e cantorias que se ouviam a longas distâncias. Também apresenta uma compilação de registros relativos à prática do batuque na Amazônia e aponta os escritos de Tó Texeira (músico negro) como registros cultivadores do batuque em "arraiais" (festejos em ruas públicas) pelos anos de 1900 e 1915 no Pará. Ele cita outras obras, músicas, contos e poesias como "Um samba a luz do sol” de Juvenal Lavares (1895), que descreve o batuque no baixo Tocantins e em "A mata submersa" de Peregrino Junior (1960) que registra no Baixo Amazonas, negros envolvidos com danças, sapateados, umbigadas, rebolados e gingados sob o som do batuque.

$\mathrm{Na}$ mesma obra o autor aponta outra variação do batuque tomando como referência às determinações do Código de Posturas municipais de Belém/PA no contexto da economia da Borracha, em 1880, no qual se proibia fazer batuque ou samba. Atrelouse o batuque a atividade de "casas de samba" e "terreiros" confundindo-se com práticas

\footnotetext{
${ }^{10}$ É uma tradição afro-amapaense festivo/religiosa que reúne ciclos geracionais em um período do ano denominado de Ciclo do Marabaixo, realizados após a Quaresma e Semana Santa dentro da religião católica (VIDEIRA, 2009). Sobre o Marabaixo, Silva (2014) sustenta as ponderações do pesquisador Nunes Pereira ao destacar a dança praticada por mestiços e negros em geografia bem definida para o Estado do Amapá. Mazagão Velho, bairro do Laguinho e antigo quilombo do Curiaú teriam sido os pontos de encontro desta manifestação cultural de origem malê ou sudanesa.
}

MARGENS - Revista Interdisciplinar 10 anos de Margens - Dossiê: Olhares para o campo... Versão Digital - ISSN: 1982-5374 
curativas, pajelanças, benzedeiras e xamãs afro-indígenas, ao que registra José Veríssimo para os anos de 1878. Em linhas gerais, o autor confere ser mais lucido considerar o batuque como expressões culturais de danças e percussões acompanhados de cantorias coletivas em espaços públicos e quanto à nomenclatura, o termo teria derivação do termo africano "bater", talvez "batchuque" ou "baçuque", com possibilidade de ser originário do Congo ou Angola.

Outra obra importante é "Batuque", de Bruno de Menezes que apresenta compilação de poesias e cantos que refazem laços entre Brasil e África, demonstra aproximação entre as práticas culturais e as singularidades do Batuque praticado no Estado do Amapá, dando foco, a comunidade quilombola São Pedro dos Bois. No prefácio da obra, Josse Fares e Paulo Nunes (2005) apresentam interessante digressão sobre os sentidos da obra e anunciam ver a poesia se transformar em punhais que se erguem para gritar denúncias e indignações. Na poesia "Batuque" o autor ressalva: "mãe preta deu sangue branco a muito sinhô moço" (MENEZES, 2005, p.20), e mais a frente revela a corporeidade manifestada na encenação da dança ao dizer: "[e] rola e ronda e ginga e tomba e funga e samba, a onda que afunda na cadência sensual. O Batuque rebate rufando banzeiros, as carnes retremem na dança carnal" (Ibid.). O envolvimento entre corpo, percussão e ritmo são características do Batuque e do Marabaixo sempre acompanhados de cantarias e ruídos dos tambores, símbolo da percussão negra em Macapá.

O Batuque em Macapá, segundo Silva (2014), tem tradição na zona rural nas comunidades quilombolas de Curiaú, Ilha Redonda, Igarapé do Lago, Mazagão, São Pedro dos Bois entre outras. $\mathrm{O}$ autor faz referência à revista "Tambores no meio do mundo: O rufar da cidadania" organizada pela Secretaria Especial de Políticas para Afrodescendentes - SEAFRO/AP, para sustentar que o "batuque" tem suas origens no Amapá desde o século XVIII, contexto do processo de ocupação da Vila de São José (Macapá) e Mazagão. Para ocupar a região foram trazidos negros na condição de escravos da África, Pará e Maranhão e nessas terras introduziram a “cultura do tambor”. Para o autor, o batuque em Macapá foi organizado pelos escravos com objetivo de comemorar as parcerias e a união dos seus pares por meio da dança e de reuniões alegres. Portanto, diferentemente do Marabaixo, o Batuque não reproduziria sofrimento e delações do tempo da escravidão e sim o arrefecimento da cultura africana e afro-brasileira nas terras 
do Amapá como símbolo de pertença e continuidade de tradições ancestrais marcadas por momentos de cortejos e comemorações.

É importante frisar as semelhanças e as diferenças que tornam o Batuque e o Marabaixo manifestações singulares apesar das continuidades e atravessamentos de características existentes entre elas. Outra peculiaridade é a denominação dada aos cantos e versos entoados. No marabaixo eles são chamados de "ladrões" e no batuque de "bandaias" ou "cantiga de batuque" (VIDEIRA, 2013). A autora também ressalta que essas manifestações possuem traços que se assemelham a tradição Bantu (grupo etnolinguístico localizado principalmente na África subsaariana).

Essas singularidades também são anunciadas na fala do senhor "Paredão", membro da comunidade quilombola São Pedro dos Bois, ao informar que o Batuque é uma dança alegre que em seus versos cantam o cotidiano da comunidade. Destacou ainda, que os mais antigos relatam que o Batuque era um misto de danças e músicas executadas em épocas de boas colheitas para patrões e escravos. E é nessa perspectiva cultural que entra o trabalho da escola da comunidade, resgatando a festividade da manifestação.

Videira (2013), em seu Livro "Batuques, folias e ladainhas, a cultura do quilombo do Cria-ú em Macapá e sua educação" organiza de certa maneira, uma arqueologia das simbologias do quilombo remanescente mais conhecido do Amapá, o Curiaú. Apresenta suas territorialidades marcadas pelo corpo, pelo tempo e perspectivas contemporâneas fortemente demarcadas pela necessidade da preservação dos seus bens naturais, materiais e imateriais. A autora amplia a discussão para a área da educação apontando-a como um importante meio de resgate e preservação das ancestralidades afro-brasileiras. Assim como apontam as perspectivas do fazer escolar na comunidade São Pedro dos Bois, localizada a cerca de uma hora de distância do Curiaú, proximidade reforçada pelo parentesco existente entre muitas famílias nas duas localidades.

\section{Educação e arte: Batuque na escola}

$\mathrm{Na}$ antiga casa da matriarca Gregória reuniam-se os filhos da comunidade para ter acesso às primeiras letras (alfabetização), com o passar do tempo e maior complexidade da organização comunitária, já pelos anos de 1940, sentiu-se a necessidade de um prédio com fins específicos para a formação escolar. Somente em 1965 sob o governo do então coronel Janary Gentil Nunes iniciou-se a construção do prédio escolar que após conclusão 
homenageou o primeiro professor da comunidade: "Texeira de Freitas", oficializando-se na década de 1980, como "Escola Estadual Teixeira de Freitas", como informa a documentação fornecida por Anny Picanço Barbosa, se auto identifica quilombola e está secretária da escola.

Em entrevista, Anny Barbosa relatou aspectos do fazer escolar e informou que em São Pedro dos Bois: “[...] as atividades pedagógicas primam pela união, trabalho em equipes, onde não há um gestor que manda e outros obedecem, mas sim, todos trabalham em conjunto em prol da comunidade". Os serviços na escola são realizados por funcionários moradores próximos ou descendentes do próprio quilombo. Assim, escola e comunidade atuam juntas, em tudo o que for necessário. A educadora também referiu-se a estrutura física e pessoal ao informar que lá trabalham cerca e 30 funcionários, onde 90\% são da própria comunidade, assim como a diretora, os(as) docentes e a própria secretária. A escola em seu projeto original possuía duas salas de aula, porém, em virtude do aumento da demanda de discentes estas salas foram transformadas em cinco onde os antigos alojamentos dos professores passaram a ser utilizados como salas de aula.

Atualmente a escola funciona com cinco salas, quatro regulares e uma de ensino especial, além de dois corredores, cozinha, depósito interno e externo, sala de leitura compartilhada com o espaço da secretaria, laboratório de informática, diretoria, um banheiro adaptado e três banheiros regulares. A comunidade escolar conta com turmas de ensino fundamental I e II, em dois turnos (matutino e vespertino), com uma sala específica para o atendimento de alunos com necessidades especiais. Pela manhã funciona o ensino fundamental I ( $1^{\circ}$ ao $5^{\circ}$ ano) e pela tarde, o ensino fundamental II ( $6^{\circ}$ ano ao $9^{\circ}$ ano $)$, essas turmas utilizam materiais didáticos adquiridos com recursos Federais e Estaduais. Os recursos para compra de merenda são específicos para a região quilombola, pois o cardápio é diferenciado.

Entre os projetos pedagógicos realizados pela escola, o mais importante é o "Projeto Batuque" (figura 1), manifestação artística marcante da cultura local, sendo estudada e colocada em prática, especialmente, pelos(as) discentes com vias a recuperar e reavivar entre os jovens o respeito pela tradição do seu povo. Com o projeto, conhecem, escrevem, aprendem, visualizam e produzem, criam e recriam, atualizando ladainhas, utilizadas como bandaias para as rodas de Batuque. Nas elaborações das ladainhas 
problematizam temas como: racismo e religião ${ }^{11}$ no intuito de reconhecer e valorizar essa cultura por meio de processos educativos.

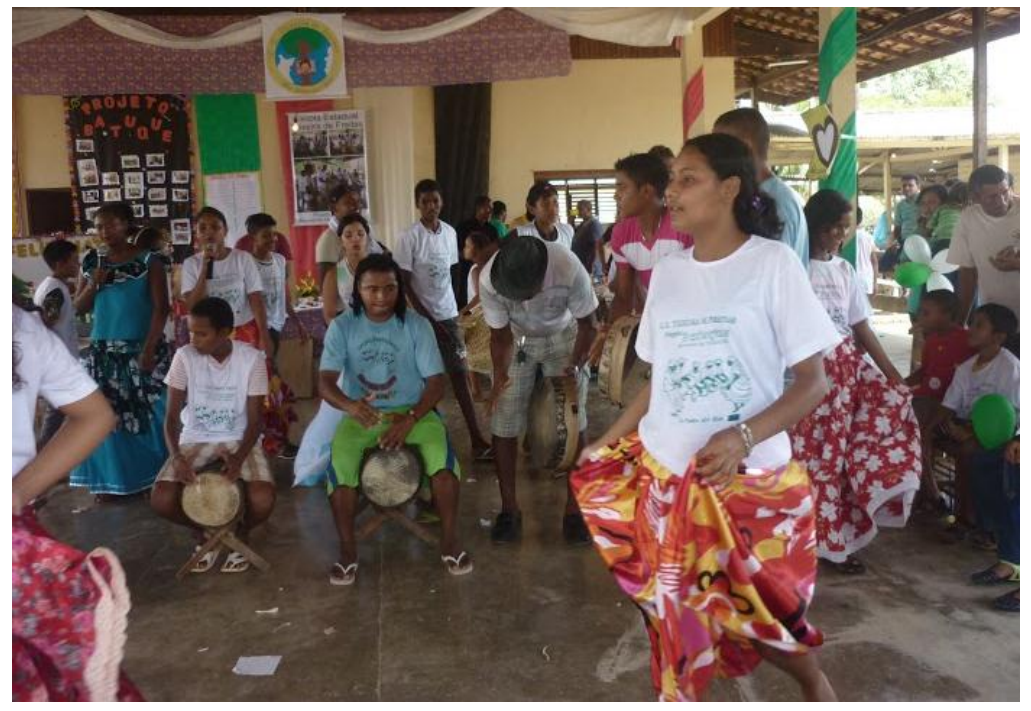

Figura 1 - Realização do Projeto Batuque: apresentação de música e dança em novembro de 2014. Fonte: Atividade de campo, 2015, arquivo dos autores.

Como partícipe do fazer educacional, Anny Barbosa informou: “[...] a educação tem como papel social, a formação e sistematização de seus conhecimentos, incluindo valores e sua cultura". Amplia: "fazer entendê-lo como quilombola, precisa aproximar educação e cultura". E conclui falando sobre as perspectivas para o futuro: “[...] é de que os filhos da escola possam crescer, adquirir conhecimento, se formar e voltar para a comunidade, ajudando no progresso das futuras gerações, não importando a sua formação". Ao que parece a escola sistematiza e atualiza o conhecimento empírico que alunos e alunas vivenciam no cotidiano da comunidade e nas manifestações artísticas/religiosas que fazem o calendário escolar e o calendário da comunidade.

O Projeto Pedagógico Batuque que acontece na escola anualmente entre os meses de outubro e novembro apresenta em seu objetivo geral registrado no documento oficial: “fomentar a valorização da produção popular como um patrimônio cultural da história do povo da comunidade São Pedro dos Bois", anuncia-se como interdisciplinar por envolver diferentes docentes/disciplinas, atinentes ao currículo escolar. Apresenta-se a

\footnotetext{
${ }^{11}$ Estas informações conferem parte do relatório de pesquisa elaborado por Adrian Kethen P. Barbosa, discente do curso de História da Universidade Federal do Amapá em atendimento as atividades preliminares do projeto de iniciação científica "Mapeamento social, diversidade e territorialidades no Estado do Amapá" ainda em processo de registro, sob a coordenação do prof. Me. Raimundo Diniz.
} 
compreensão de que constitui a maior expressão da cultura de São Pedro dos Bois, responsável pela identidade artística, histórica e cultural, por isso, merece ser preservado. Justifica-se por cultivar a integração entre conhecimentos da educação escolar e saberes, indivíduos e comunidade, com perspectiva voltada para a educação popular como ampara Paulo Freire.

Em sua organização metodológica o Projeto Batuque em documento prescreve relações multisseriadas congregando discentes do primeiro ao quinto ano e outro bloco, do quinto ao nono ano, reunindo docentes em três etapas: Fase teórica (pesquisa bibliográfica e etnográfica); Fase prática (oficinas, pesquisas de campo e produções artísticas); e, Fase final (culminância dos trabalhos). Durante as fases, alguns trabalhos são realizados com o apoio de instituições não governamentais e profissionais do Programa Educacional Mais Educação ${ }^{12}$. As vestimentas, os instrumentos, algumas letras de músicas e a ornamentação da escola, são elaboradas, preferencialmente, pelos discentes e docentes com materiais apropriados da região e a outra parte é comprada com recurso previsto no orçamento da escola. A última fase é a avaliação do projeto feita com a participação de toda a comunidade escolar.

A maquete (figura 2), confeccionada artesanalmente, exposta no espaço escolar, reproduz características singulares do Batuque ao sugerir movimentos de roda, usos de instrumentos e vestimentas cuidadosamente confeccionadas, reforçando visualidades, corporeidades e manifestações étnicas, características de grupos quilombolas. A diversidade de cores e a formação de um grupo referendam aspectos da cultura negra comunitária facilmente encontrada entre os quilombolas de São Pedro dos Bois. A materialização das compreensões sobre o Batuque dadas por meio da maquete sintetiza o conjunto de aprendizagens, trocas, reproduções e representações sociais manifestadas no fazer escolar e no cotidiano da comunidade. Pois os processos de subjetivações que envolvem a relação entre a escola e a comunidade potencializam-se e expandem-se para fora dos "muros" da instituição propagando-se e constituindo-se de outros sentidos que depois voltam e adentram novamente na escola em um constante devir.

\footnotetext{
12 Programa Federal que tem por finalidade contribuir para a melhoria da aprendizagem por meio da ampliação do tempo de permanência de crianças, adolescentes e jovens matriculados em escola pública, mediante oferta de educação básica em tempo integral (DECRETO N 7.083, DE 27 DE JANEIRO DE 2010). 


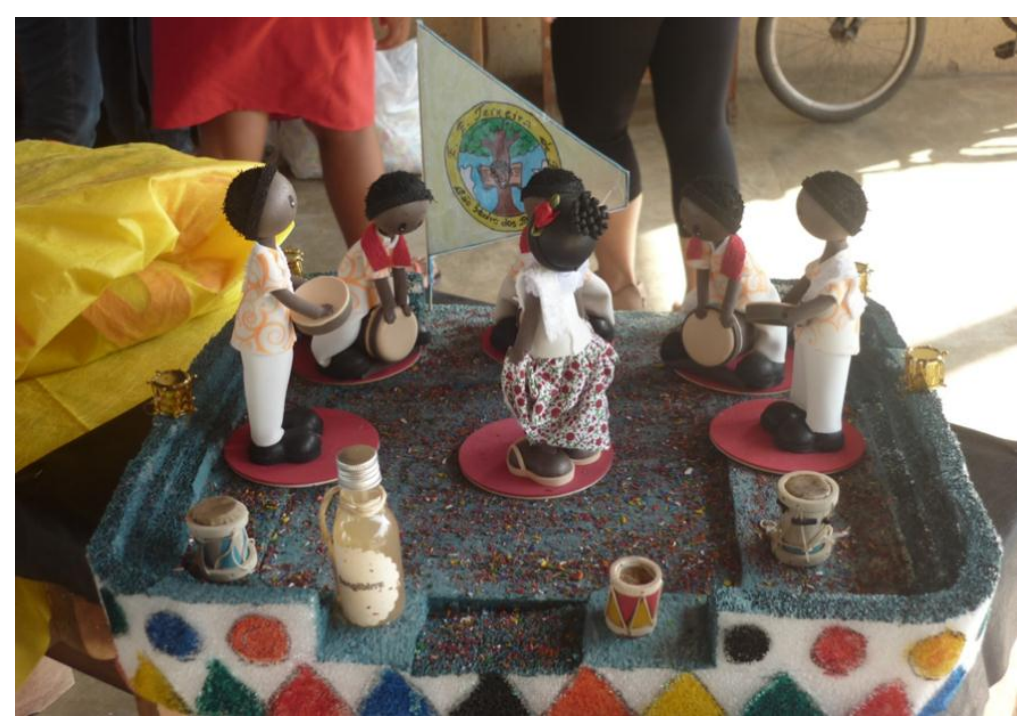

Figura 2 - Maquete reproduzindo o "Batuque" em São Pedro dos Bois - Artefato usado como decoração do espaço escolar. Fonte: Atividade de campo, 2015, arquivo dos autores.

As etapas de elaborações do Projeto Batuque são acompanhadas por diversas estratégias de apropriações das riquezas socioculturais e ambientais inerentes à comunidade, traduzidas no desenrolar do processo de culminância através da apresentação do casal cultural, venda de comidas típicas, declamações de versos, elaborações de letras de músicas, criações de ritmos, percussões e danças devidamente ensaiadas. As elaborações conferem momentos de sociabilidades, interações sociais, companheirismos e laços de solidariedades, como também atenuações de situações de conflitos mediadas por decisões coletivas.

Estes momentos de sociabilidades que transbordam o espaço da sala de aula e promove a interação com a comunidade (figura 3) prescreve valorização de outros sujeitos entre quais os idosos são incluídos pela importância da memória viva para a preservação da cultura. Os conteúdos trabalhados são apropriados e os temas referendam situações sociais encontradas no desenrolar das narrativas, nas visualidades do fazer escolar, da vida comunitária, do modo de vida singular em reciprocidade e diálogo com a natureza viva, dançada, cantada, partícipe do processo de formação educacional. 


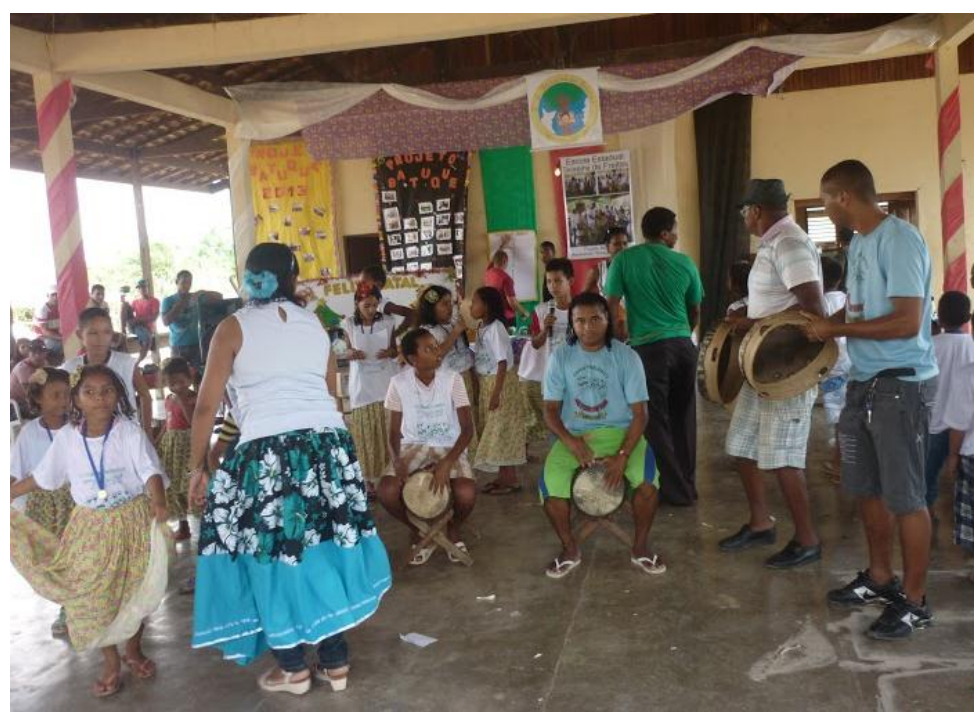

Figura 3 - Integração entre escola e comunidade no Projeto Batuque. Fonte: Atividade de campo, 2015, arquivo dos autores.

Os mais idosos participam do processo quando reproduzem comportamentos e narrativas com vias a recuperar da história da cultura local, comunitária e familiar. Tais condições refletem ajudando-os a se posicionar como quilombolas nos discursos engendrados, ou seja, aqueles construídos, idealizados ou inventados e disseminadores de relações históricas, de práticas concretas e vivas. Amplamente problematizados por Foucault ao compreendê-los para além de uma "estreita superfície de contato, ou de confronto, entre uma realidade e uma língua, [...] mas como práticas que formam sistematicamente os objetos de que falam" (FOUCAULT, 1986, p.56). Portanto, o fazer escolar, por esse prisma, se atina a cultivar noções de pertencimento e liberdade política para poder "dizer sobre si”, sobre sua comunidade e assegurarem lutas por direitos e valorização da cultura, identidade e território quilombola.

As práticas artísticas são comumente empregadas nas realizações de projetos escolares, principalmente quando estes estão relacionados com questões culturais, dando aos professores(as) e alunos(as) a grande responsabilidade de pensar, planejar e executar o processo de ensino e aprendizagem com perspectiva interdisciplinar. Mais que um fazer/discurso mecanizado, a dinâmica da interdisciplinaridade evoca práticas de trocas múltiplas e diversificadas entre todas as áreas do currículo escolar, articulando-as em a favor do tema gerador, no caso apresentado, o Batuque.

Neste estudo, o Batuque é concebido como dispositivo educativo, tal como discute Jorge Larrosa (1994), ampliando o seu sentido pedagogicamente para além do controle 
do currículo, tido como regimes hierárquicos de saber e poder. É compreendido como entidade que constrói e medeia a relação do sujeito consigo mesmo. Para o autor, "um dispositivo pedagógico será, então, qualquer lugar no qual se constitui ou se transforma a experiência de si. Qualquer lugar no qual se aprendem ou se modificam as relações que o sujeito estabelece consigo mesmo" (LARROSA, 1994, p. 57). Ou seja, o batuque, dentro ou fora das práticas escolares é uma entidade repleta de ensinamentos e aprendizagens que confluem para o autoconhecimento e o conhecimento do outro, construindo processos dinâmicos de subjetivação e alteridade que se desenvolve em solos férteis de tensões.

\section{Considerações finais}

No movimento cadenciado do corpo, ao som forte do tambor, acompanhado por vozes melodiando bandaias de Batuque as gerações das matriarcas Ana Barriga e Gregória falam de situações do cotidiano e de temas religiosos revelando pistas de um discurso engendrado por relação de poder, resistência e ancestralidade afro-amapaense. Nossas considerações finais são notas que revelam interesses de continuar investigando sobre as singularidades da cultura do Batuque na comunidade São Pedro dos Bois e seus desdobramentos como prática social, pois quanto mais conhecemos, mais nos damos conta de que ainda se tem muito, a saber.

Continuar ouvindo as narrativas contadas por moradores de todas as idades, encadeadas por diversos pontos de vista, acessar narrativas escritas e imagéticas, comparar dados e cruzar informações nos possibilitará novas percepções sobre o contexto demarcado por temporalidades distintas, que se coadunam na cotidianidade da comunidade. São pistas que nos fazem questionar: como são as estratégias de resistências dessa comunidade remanescente de quilombos para serem reconhecidos de fato e de direito? Como os moradores se percebem no duplo de sujeito ativo e/ou passivo dessa história? Que outras práticas escolares visam articular os saberes da cultura local com as demandas do currículo escolar? Na dinâmica das relações de poder, como a comunidade atua politicamente no cenário contemporâneo? Essas e outras perguntas nos mostram a impossibilidade de esgotamento do tema.

O engajamento de grupos comunitários e pesquisadores sobre a cultura afrobrasileira tem dado maior visibilidade às necessidades da preservação do patrimônio 
cultural local e sobre como esse conjunto tem se incorporado ao patrimônio nacional, configurando novos espaços de luta política e de afirmação da herança africana na formação cultural do Brasil. Falar sobre como as africanidades se desdobram e permeiam a cultura amapaense é uma necessidade afirmativa também, que podem revelar importantes facetas históricas nos permitindo confrontar e analisar diferentes modos de ver, dizer, pensar e agir no tocante as comunidades quilombolas do Amapá. Consideramos a comunidade São Pedro dos Bois um campo profícuo de saberes para reflexões e aprendizados sobre como a educação escolar, com todas as suas áreas de ensino, em um difícil exercício interdisciplinar, pode ser um alargamento do cotidiano comunitário e vice versa. Em uma interação rica de possibilidades que podem se expandir para além das territorialidades locais.

\section{Referências}

ALMEIDA, A. W. B. Terra de quilombos, terras de indígenas, "babaçuais livres", "castanhais do povo", faixinais de fundo de pasto: terras tradicionalmente ocupadas. 2 Ed, Manaus: PSGCA / UFMA, 2008.

CASTRO, M. L. V. de. Patrimônio imaterial no Brasil (Org.). Brasília: UNESCO, Educarte, 2008.

FOUCAULT, M. A Arqueologia do saber. Rio de Janeiro: Forense, 1986.

LARROSA, J. Tecnologias do eu e educação. In: SILVA, T. T. O sujeito da educação. Petrópolis: Vozes, 1994, p.35-86.

MARTINS, R. Narrativas visuais: imagens, visualidades e experiência educativa. In. VIS - Revista do Programa de Pós-Graduação em Arte. Brasília, Editora Brasil, V. 8, n. 1, Jan-Jun. de 2009, p. 33-39.

MENEZES, B. Batuque. Belém (s/n), 2005.

NASCIMENTO, E. A. do. Singularidades da Educação da Cultura Visual nos deslocamentos das imagens e das interpretações. In. MARTINS, R.; TOURINHO, I. (Orgs.). Educação da cultura visual: conceitos e contextos. Santa Maria: Ed. da UFSM, 2011, p. 209-226.

OLIVEIRA, M. do S. dos S., (org.). Relatório antropológico de caracterização histórica, econômica, ambiental e sócio cultural da comunidade São Pedro dos Bois. Amapá. Fundação Marco Zero/ Universidade Federal do Amapá- UNIFAP. 2012.

SALLES, V. Vocabulário crioulo: contribuição do negro ao falar regional amazônico. Belém. Instituto de Arte do Pará - IAP, Programa Raízes, 2003. 
SILVA, A. J. S. da. A cultura negra no Amapá. História tradição e políticas públicas. Edição do autor, 2014.

VIDEIRA, P. L. Marabaixo, dança afrodescendente significando a identidade étnica do negro amapaense. Fortaleza: Edições UFC, 2009.

Batuques, folias e ladainhas: a cultura do quilombo do Cria-ú em Macapá e a sua educação. Fortaleza: Edições UFC, 2013. 